\title{
Framework for the use of official occupational accident investigations as a learning tool: analysis of a public programme for accident investigation in the manufacturing sector
}

\section{Jesús Antonio Carrillo-Castrillo* and Luis Onieva}

University of Seville,

Camino de los Descubrimientos sn,

41092 Seville, Spain

E-mail: jcarrillo@io.us.es

E-mail: onieva@us.es

*Corresponding author

\begin{abstract}
Accident investigation is a useful tool for safety science. The use of accident investigation as a learning tool at the macro level necessitates specific requirements quite different from the usual needs at the company level. A proper codification system and information on the accident scenarios are needed to let safety practitioners identify if the information is useful for the organisations they are assessing. In the same way epidemiological tools have been applied to the analysis of circumstances of accidents, the epidemiological statistical tools can help to draw conclusions for a set of investigated accidents. Our case study includes the description of the dataset used in a programme for learning from accidents in Andalusia: 'Pudo haberse evitado' (this can be translated as 'This could have been prevented'). This paper covers the requisites for a macro-level learning programme and the possibilities of analysis of the dataset in a 'research to practice approach'.
\end{abstract}

Keywords: learning from accidents; accident causes; differential causation; risk assessment; manufacturing sector; public programmes.

Reference to this paper should be made as follows: Carrillo-Castrillo, J.A. and Onieva, L. (2014) 'Framework for the use of official occupational accident investigations as a learning tool: analysis of a public programme for accident investigation in the manufacturing sector', Int. J. Risk Assessment and Management, Vol. 17, No. 3, pp.212-232.

Biographical notes: Jesús Antonio Carrillo-Castrillo is an Industrial Engineer and has an MSc in Manufacturing Engineering. He worked for seven years in the private sector as Director of Total Quality and as Safety Engineer before joining public sector in 2002. Since 2006, he is responsible for 'Safety at Work' promotion in the Regional Government of Andalusia.

Luis Onieva is a Professor of Industrial Engineering of the University of Seville since 1995. He obtained his $\mathrm{PhD}$ in the same university in 1986. His research interests covers operations research and management. 


\section{Introduction}

Accident investigation is a useful tool for safety science. At the company level, accident investigation is the closing element in the continuous improvement loop of safety management. A well-performed investigation can help an organisation discover failures in safety activities and review risk assessment.

Risk assessment is a prospective activity but it should consider those events that show those threats that have already materialised. In fact, most risk assessment methods (Willquist and Törner, 2003) are based on likelihood and consequence estimations. Using accidents for that purpose is fortunately not possible because accidents are a very rare event.

The study of how accident investigation can be used at the company level is a growing area of research. However, there is another challenge in developing the way other organisations and safety practitioners can learn from other accident investigations. There are many small and medium organisations where the number of accidents, unfortunately, is too low to let them learn from their own mistakes.

In addition, governmental institutions for health and safety are interested in developing programmes to fight the most common causes of accidents.

One possibility is sharing experiences and information from accident investigation at the company level. Social networks, associations of safety practitioners and public repositories can be used for that purpose. In fact, in most countries enterprises are required to perform an investigation for all accidents with workers with damages that need at least one day off. However, unless a common system is adopted, the identification and learning can be difficult as far as each company uses different criteria in the accident reports.

Another possibility is public access to official accident investigations performed by labour authorities. In this case, it is easier to define a common system and easier for safety practitioners to draw useful conclusions in their activity.

In both cases, it is necessary to agree on a certain accident model and a methodology of investigation that can be easily understood by safety practitioners with different backgrounds.

There are many accident investigation methods. The reviews made of the most used accident investigation methods show that there are at least four different levels: work and technological system, staff, management and company level (Sklet, 2004) and that accident investigation methods need to be aligned to the accident causation model (Katsakiori et al., 2009). In addition, the accident model needs to include at least three subsystems: technical, human factors and organisation (Van Wassenhove and Wybo, 2002).

The selection of the accident investigation method, in order to help the shared learning process, should be done taking into account those levels and subsystems but also concepts related to the complexity of the industry as coupling and tractability. For example, manufacturing accidents, in terms of complexity, are suitable for an epidemiological approach because of their loose coupling and high manageability (Hollnagel, 2008).

There is a huge challenge for research in this field. Each accident is in some way unique and any attempt to group or categorise different accidents together implies the loss of important pieces of information. Nevertheless, safety engineers need to know why 
accidents are occurring and what can be improved, and to do so the most effective way is to code main circumstances and causes in order to make easier the analysis.

The aim of this paper is to construct a framework for the use of official accident investigation as a tool for learning, with an application to a specific programme for the official accident investigation of accidents in the manufacturing sector of Andalusia, beginning in 2004. Although this is a case study, the framework proposed can be useful in other regions or sectors.

The manufacturing sector is defined as all activities with a NACE economic classification from 15 to 27 according to Council Regulation EEC No. 3037/1990. Manufacturing is the sector with the highest number of annual days of absence because of accidents in Europe (European Commission, 2009). For accidents with more than three days of absence in the European Union and Norway in 2007, the latest incidence rate of the manufacturing sector published by Eurostat is 3,097 accidents per 100,000 workers.

It is important to add that Andalusia is one of the biggest regions of Europe, and represents approximately $12 \%$ of the Spanish manufacturing sector and employs on average more than 200,000 workers.

\subsection{State of the art: epidemiology of causes of accidents research}

In the same way most of the health and safety institutions have been delivering and publishing data on the circumstances of accidents, some of them have already started to gather information on the most frequent causes of accidents.

In the USA, the Fatality Assessment and Control Evaluation (FACE) programme developed by the National Institute for Occupational Safety and Health (NIOSH) in collaboration with the state occupational safety departments published investigation reports in order to allow the identification of factors that contribute to these fatal injuries. This information is used to develop comprehensive recommendations for preventing similar deaths. This programme began in 1982. The primary intent of this programme is to provide interested users with access to the full text of hundreds of fatality investigation reports (see http://www.cdc.gov/niosh/face/default.html, accessed on 27th May 2013). The identification of an accident scenario or causes is not coded (Higgins et al., 2001).

In Europe, probably one of the best public programmes in terms of the information published is performed by the Danish Labour Inspectorate. A software tool called Storybuilder helps by entering accident paths into a graphically enhanced database. Analysis of the accident paths provides information about the direct and root causes of accidents (see http://www.rivm.nl/en/Topics/Topics/S/Storybuilder, accessed on 27th May 2013). Information can be produced about immediate causes and the root causes that can be traced back to management tasks. Based on the analysis of over 9,100 accidents investigated by the Labour Inspectorate, generic accident scenarios were developed. They represent specific types of accidents. A total of 36 generic accident models were composed, ranging from falls from height accidents to confined spaces, explosions, etc. There are approximately 26,000 accidents available for further consultation.

In Portugal, the CAPTAR - 'learn to prevent' project uses a methodology based on the Work Accidents Investigation Technique (WAIT) (Jacinto and Aspinwall, 2003). Some initial results have been published but the number of accidents investigated is low so far. 
The analysis of this huge amount of data needs some requisites to be useful for safety practitioners. The purpose of this paper is to analyse the development of a public programme analysis of the causes of occupational accidents in Andalusia, Spain, and to propose future improvement areas for this kind of programmes.

\section{The requisites for a common framework in learning from accidents at the macro level}

In this section we have identified those elements that are required for a learning programme at the macro level. All of them have been integrated into the Andalusian initiative in progress as an action of the First Andalusian Strategy of Occupational Health and Safety at Work for the period 2010-2014. Results and discussion are based on the accidents investigated within the manufacturing sector.

\subsection{The need for an objective}

Any programme needs to have a clear objective. In our programme the objective is to offer small and medium organisations a complete set of identified causes. Even though they did not experience those events, they can learn from the lessons and include hazards and threats for preventive barriers identified in the investigations to their risk assessment.

\subsection{The need for a common identification of accident scenarios}

As the learning process and also the risk assessment process needs a clear identification of the accident scenario these variables need to be properly coded. Although some of the full reports are being published on the web (Junta de Andalucia, 2012) and disseminated in a periodical bulletin with more than 3,000 safety experts as receivers, the overall conclusions from the official accidents investigated can only done efficiently through statistical analysis.

To be effective, results need to be presented considering the activities, tasks, accident mechanisms, types of organisations and personal factors. Only with that approach can the analysis be applied to the possible accident scenarios in each organisation.

A group of accidents from the same scenario would share a common internal structure in terms of the exposure and circumstances leading to the accident occurrence. Phase III of European Statistics on Accidents at Work (ESAW) (European Commission, 2002) covers harmonised variables and classifications of the circumstances of accidents at work establishing the situation and conditions prevailing at the time of the accident. Therefore, the identification of the scenarios can be done using the taxonomy of ESAW.

From the preventive point of view, what constitutes the scenario of the accident is the combination of variables, as they define the previous conditions existing when the accident took place and the mechanism of the accident itself. In ESAW, there is an implicit identification of accident scenarios as a combination of the following variables: work in process, physical activity, deviation and contact (Jacinto and Aspinwall, 2004).

Analysing accidents with the same scenario is easy to understand by safety practitioners. It is important to consider that risk assessment is performed through the identification all the possible hazards in each of the tasks. 
In Spain, accident reports are electronically collected in 'Official Workplace Incident Notification Forms'. All accidents that result in an absence from work of one or more days must be notified. Medical criteria are applied to classify the accident as minor or non-minor, depending on the severity of injuries. For each accident reported, we have information about worker age, months of experience in the company, occupation, and some technical circumstantial information both from workers and companies.

If we considered the preventive point of view, and the risk assessment practice, there are two main underlying concepts that are used to identify an accident scenario: task and accident mechanism.

First, it is what the worker was doing as it would determine the risk exposure in most cases. We use the concept of task to identify those circumstances. One job can include several task or activities (Aneziris et al., 2010). Tasks are identified through the variables working process and physical activity. According to ESAW, Working Process is the "main type of work or task (general activity) being performed by the victim at the time of the accident" and Physical Activity is "the victim's exact 'Specific Physical Activity' at the instant of the accident." For example, one task is maintenance using hand-held motorised tools (ESAW codes, 52 for working process and 22 for physical activity).

The second concept, it is what happened leading from normal work to the accident occurrence. We use the concept of accident mechanism to identify those circumstances. The accident mechanism is used to identify each central event of bow-ties and it is defined by the combination of a deviation and a mode of injury (Hale et al., 2007). According to ESAW, Deviation is "the event that triggers the accident" and mode of injury is "the contact that injured the victim". For example, one accident mechanism is a fall of a person to a lower level with a crashing on or against as a result (ESAW codes, 51 for deviation and 31 for mode of contact).

It must be remarked that this model of the accident scenario is based only on the technological subsystem. Other subsystems, such as human factor and organisation, unfortunately are not yet developed with the same level of detail in the coding system of ESAW (Jacinto et al., 2009).

Another limitation is the limited codes available. Although task and accident mechanisms can be different within the same ESAW codes, at the same time it is the only way to convert a case-to-case analysis into a sort of epidemiological approach where all the accidents similar enough to be equally coded can be analysed to discover associations and common patterns.

\subsection{The need for a common accident investigation method}

Several accident models and investigation methods have been proposed (Sklet, 2004). Although there are possibly more sophisticated methods, it is more important for most of the occupational accidents that the results are easy to understand and to disseminate. Most of the complex investigation methods apply to results that are not applicable to small organisations.

In Spain, as it is promoted by most of the labour administrations, the most used method is the fault tree. In fact, the guide for accident investigation used that method and it is the method used by public officers when they perform an official accident investigation. This methodology is based on a cause tree model (Høyland and Rausand, 1994). 


\subsection{The need for a common codification system for accident causes}

For a long time, accident reports have been reported without any standardisation. In the last decades, with the direction of the International Labour Organization (1998), most countries have adopted statistical classifications that allow the comparison and analysis of the main circumstances of the accidents.

In Europe, ESAW (European Commission, 2002) have introduced important variables such as physical activity, work in process, deviation and contact, among others. However, in relation to the classification of causes, there is no complete codification system as far as we know. There are partial codification systems for human error (Shappell and Wiegmann, 2001) or organisational and environmental causes (Jacinto and Aspinwall, 2003).

According to the Encyclopaedia of International Safety Organization Part VIIIChapter 56 (International Labour Organization, 1998), causes of accidents should be classified as immediate causes (unsafe acts, unsafe conditions) and contributing causes (safety management performance, mental condition of workers and physical conditions of workers). According to the latest studies, both latent and active failures need to be taken into account in order to explain accident causation (Reason, 2000). Accident investigations combine both immediate and environmental causes in order to explain both the accident physical event and the latent conditions that contributed to the accident occurrence. Any codification system should address all these categories of causes.

In narrative analysis, researchers use a coding system performed in a second step using previous accident report submissions so they are coded by a person who did not have direct information about the accident (Lincoln et al., 2004).

Although we gathered every year a large number of accident notifications with narrative descriptions, we have discarded them for this study due to the lack of accuracy and the limited information provided by accident reports. Therefore, we chose accident investigation reports as they have more accurate information and because the main causes were coded at the same time the accidents were being investigated.

In certain occasions, as when the accident is non-minor, if it is required by justice or labour inspectors or according to random selection of cases, official safety experts conduct an official accident investigation. These investigations are developed according to internal procedures and an official extended investigation report is submitted.

Since 2003, Instituto Nacional de Seguridad e Higiene that is the Occupational Health and Safety Institute in Spain, has promoted a codification system for causes included in official accident investigation reports in order to facilitate the statistical analysis. There are 255 possible cause codes grouped as workspace conditions, protection and service installations, machines, other equipment, materials and substances, work organisation, safety management and personal factors (Fraile, 2011). In 2004, the Labour Authority in Andalusia adopted a common codification system for the causes identified in official accident investigations. Data is also available for accident circumstances collected from accident notification following the EASW. The full coding system is listed in the Annex.

In the coding system, codes are defined with four digits, the first digit identifies the group of causes, the first two digits identify the subgroup of causes and the last two digits are the different causes in each subgroup. For example, cause 7206 is 'inadequate training/information about risks of preventive measures', classified as group 7 (safety management, latent) and the subgroup 72 (preventive activities). 
Most active (immediate) causes are classified in the groups with first digit 1 to 5 and most of the latent causes are classified in the groups 6 to 8 are latent (Reason, 2000). Groups are considered on the type of cause (the cause type identifier is the first digit of the code). Within each group, there are several subgroups. Subgroups are considered the subtype of cause (the cause subtype identifier is the first two digits of the code). See Table 1 for the distribution of the causes in groups.

Table 1 Example of the distribution of type of causes: manufacturing sector

\begin{tabular}{llcc}
\hline Group of causes & Nature & Number of causes & Number of cases as main cause \\
\hline Workplace condition & Active & 210 & 78 \\
Installations & Active & 38 & 14 \\
Machinery & Active & 289 & 111 \\
Other equipment & Active & 163 & 54 \\
Materials and substances & Active & 78 & 33 \\
Work organisation & Latent & 758 & 191 \\
Safety management & Latent & 753 & 83 \\
Personal factors & Latent & 539 & 176 \\
\hline
\end{tabular}

The number of causes per accident investigated is variable, reaching a maximum of nine, but in most cases the number of causes is between three and five. Note that all causes are considered equally except ones marked as the main cause.

\subsection{The need for an accident causation pattern definition}

Accident pattern is defined by the combination of causes that lead to the accident. In the same way a certain combination of circumstances can identify an accident scenario, a certain combination of causes identify a causation pattern.

Table 2 Causation patterns identified example: manufacturing sector

\begin{tabular}{|c|c|c|c|c|c|}
\hline $\begin{array}{l}\text { Active } \\
\text { causes }\end{array}$ & $\begin{array}{c}\text { Organisational } \\
\text { causes }\end{array}$ & $\begin{array}{c}\text { Safety management } \\
\text { causes }\end{array}$ & $\begin{array}{c}\text { Human } \\
\text { factors causes }\end{array}$ & No. cases & $\%$ cases \\
\hline & & & $\mathrm{X}$ & 69 & $8 \%$ \\
\hline & & X & & 29 & $4 \%$ \\
\hline & & $X$ & $\mathrm{X}$ & 39 & $5 \%$ \\
\hline & $X$ & & & 74 & $9 \%$ \\
\hline & $X$ & & $\mathrm{X}$ & 40 & $5 \%$ \\
\hline & $X$ & $X$ & & 58 & $7 \%$ \\
\hline & $X$ & $X$ & $X$ & 56 & $7 \%$ \\
\hline$X$ & & & & 84 & $10 \%$ \\
\hline X & & & X & 31 & $4 \%$ \\
\hline$X$ & & $X$ & & 47 & $6 \%$ \\
\hline$X$ & & $X$ & $X$ & 37 & $4 \%$ \\
\hline$X$ & $X$ & & & 65 & $8 \%$ \\
\hline$X$ & $X$ & & $X$ & 42 & $5 \%$ \\
\hline$X$ & $X$ & $X$ & & 85 & $10 \%$ \\
\hline$X$ & $X$ & $X$ & $X$ & 71 & $9 \%$ \\
\hline
\end{tabular}


With the causes coding system adopted, causation pattern can be defined by the combination of type of causes. A type of cause is each of the groups or subgroups of causes. There may be more than one cause identified in the accident within the same type of cause. The criterion to be used is that if at least one of the causes is included within a certain type of causes, then that type of causes is part of the causation pattern. Therefore, the causation pattern is defined by the types of causes with at least one cause identified.

For example, an accident the investigation may identify causes related to personal factors, work organisation and machinery. The relative prevalence of accident patterns can be used to identify the most common combinations of causes.

Causation patterns can be analysed in terms of the scenarios of accidents and other circumstances in order to find associations. An association between causation patterns and certain scenarios or worker collectives can be a useful identification of intervention areas. See Table 2 to see an example of the causation patterns identified.

\section{The dataset}

In this section we present the information about the dataset collected from 2004 to 2011. Only within the manufacturing sector, there are 836 accidents and 2,828 causes coded.

The structure of the dataset is formed with cases in each row corresponding to an accident investigation. For each accident investigation there is information of the causes identified in the investigation performed, and if any of them is considered the main cause. Included in each row from the accident notification are the demographic variables (sex, nationality, age), the labour variables (time in the enterprise, contract type, occupation category), the enterprise variables (size, type), the work place variables (outsourcing or not, usual or not for the worker) and the variables included in ESAW-III (working process, physical activity, deviation and mode of contact).

As any dataset of cases, the analysis can be done controlling for those confounding factors included through multivariate statistical methods such as regression models or discrimination, cluster or correspondence analysis among others.

\section{Analysis of the data: research to practice approach}

Most of the literature in safety science and occupational epidemiology has been dedicated to the analysis of risk factors and their association with the circumstances of the accidents (Khanzode et al., 2012). The statistical tools used can be easily adapted to the analysis of the association of causes of accidents and the circumstances of the accidents. Moreover, the association of certain risk factors with the causes can lead to an improved understanding of how to prevent accidents.

The analysis of risk factors can only help to prioritise preventive activities, but the analysis of causes can provide the clue of how to design more effective preventive activities. With the cause analysis the purpose is not to assess the risk of accident but to identify the mechanism of the accident itself in order to adopt proper preventive or protection measures. 


\subsection{Statistical methods: differential causation}

In order to analyse the specific causes (causes with the full four digit code), differential causation between two categories of the other variables available can tested by comparison of the proportion of accidents (Kines, 2002) that includes at least one cause in each group or subgroup of causes (large sample simplified method, assuming normal distribution).

For example in Carrillo et al. (2013), the differential causation in terms of the workers characteristics was analysed for the most common accident mechanism. In Table 3, the results of the differential causation in loss of control accidents in terms of the age of the worker are presented.

Table 3 Analysis of differential causation example: loss of control accidents vs. worker age

\begin{tabular}{lcccc}
\hline & & \multicolumn{3}{c}{ Worker age } \\
\cline { 2 - 5 } Most prevalent contributing causes & No. of cases & $\begin{array}{c}\text { Young } \\
(16-24)\end{array}$ & $\begin{array}{c}\text { Senior } \\
(>55)\end{array}$ & $\begin{array}{c}\text { Normal age } \\
(25-54) \text { ref. }\end{array}$ \\
\hline Inadequate work method & & $8(11 \%)$ & $2(11 \%)$ & $24(11 \%)$ \\
Lack of training & 34 & $8(11 \%)$ & $1(5 \%)$ & $14(6 \%)$ \\
Other personal factors & 23 & $1(1 \%) \mathrm{a}$ & $3(16 \%)$ & $16(7 \%)$ \\
Removing guards or protections & 20 & $4(6 \%)$ & $1(5 \%)$ & $12(5 \%)$ \\
Not complying safety rules & 17 & $1(1 \%)$ & $0(0 \%) \mathrm{a}$ & $12(5 \%)$ \\
Not using personal protection equipment & 11 & $6(8 \%) \mathrm{a}$ & $1(5 \%)$ & $4(2 \%)$ \\
Total number of causes identified & & 71 & 19 & 221 \\
\hline
\end{tabular}

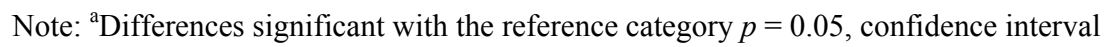
do not include 0.0 .

\subsection{Statistical methods: association and contingency tables}

The association between two categorical variables is defined by a contingency table where in each cell the frequency of each combination between the modalities of the categorical variables is counted. The overall association can be tested with chi-square.

However, in terms of prevention, what really matters is the relationship between each of the categories (modalities), thus the analysis should be performed at the cell level of the contingency tables.

Cell level relationships can be tested with phi coefficient (Chi et al., 2009). Phi coefficients are calculated between worker categories or scenarios and type of causes. For dichotomous variables, phi coefficient at cell level is equivalent to the phi coefficient for the variable.

Only positive and significant values of phi coefficients are useful for identifying association between categories. Negative values would indicate that there is little contribution of the category to the accident causation. When there is a main cause, analysis of association of main cause with other circumstances of the accident is straight forward.

As an example of the use of this statistical tool for cause analysis we present the relationship between deviations and type of causes for maintenance accidents (see Table 4). Deviation is defined as the event that triggers the accident. For instance, 
according to the phi coefficient calculation at the cell level, there is a strong association between accident with loss of control and causes related to facilities, machinery and other equipment.

Table 4 Contingency table example: deviation vs. group of causes

\begin{tabular}{|c|c|c|c|c|c|c|}
\hline \multicolumn{2}{|c|}{ Deviation } & \multirow{2}{*}{$\begin{array}{c}\begin{array}{c}\text { Workplace } \\
\text { condition }\end{array} \\
0^{*}\end{array}$} & \multirow{2}{*}{$\begin{array}{c}\begin{array}{c}\text { Installations, } \\
\text { machinery, } \\
\text { equipment }\end{array} \\
1 *\end{array}$} & \multirow{2}{*}{$\begin{array}{c}\begin{array}{c}\text { Work } \\
\text { organisation }\end{array} \\
14\end{array}$} & \multirow{2}{*}{$\begin{array}{c}\begin{array}{c}\text { Safety } \\
\text { management }\end{array} \\
12\end{array}$} & \multirow{2}{*}{$\begin{array}{c}\begin{array}{c}\text { Personal } \\
\text { factors }\end{array} \\
10\end{array}$} \\
\hline$(1 \mathrm{x})$ & $\begin{array}{l}\text { Electrical problems, } \\
\text { explosion, fire }\end{array}$ & & & & & \\
\hline$(2 \mathrm{x})$ & $\begin{array}{l}\text { Overflow, overturn, } \\
\text { leak, flow, } \\
\text { vaporisation, } \\
\text { emission }\end{array}$ & 0 & 0 & 0 & 0 & $2 * *$ \\
\hline$(3 x)$ & $\begin{array}{l}\text { Breakage, bursting, } \\
\text { splitting, slipping, } \\
\text { fall, collapse of } \\
\text { material agent }\end{array}$ & $11^{* *}$ & 6 & 16 & 9 & 10 \\
\hline$(4 x)$ & $\begin{array}{l}\text { Loss of control } \\
\text { (total or partial) }\end{array}$ & 1 & $6^{* *}$ & 7 & 7 & 2 \\
\hline$(5 x)$ & $\begin{array}{l}\text { Slipping - } \\
\text { stumbling and } \\
\text { falling - fall of } \\
\text { person }\end{array}$ & 0 & 2 & 5 & 2 & 4 \\
\hline$(6 x)$ & $\begin{array}{l}\text { Body movement } \\
\text { without any } \\
\text { physical stress } \\
\text { (generally external } \\
\text { injury) }\end{array}$ & 8 & 10 & 18 & 9 & 6 \\
\hline$(7 x)$ & $\begin{array}{l}\text { Body movement } \\
\text { under or with } \\
\text { physical stress } \\
\text { (generally internal } \\
\text { injury) }\end{array}$ & 0 & 0 & 1 & 1 & $3 *$ \\
\hline
\end{tabular}

Notes: *Phi coefficient is significant $(p<0.05)$. ${ }^{*}$ Phi coefficient is significant $(p<0.01)$.

A significant association at the cell level is useful to apply preventive measures that would be likely effective; in this case, loss of control accidents can be prevented with appropriate measure to improve safety level of equipment.

This methodology can be used to analyse the relationship of each group of causes and each circumstance, worker characteristic or risk factor as far as the analysis is performed for accidents with a similar scenario, as previously discussed.

\subsection{Statistical methods: multifactor tools}

Multifactor analysis is used when more than two variables are analysed at the same time. As in any cross-sectional analysis, and the analysis of accident causes is a cross-sectional one, there is a threat of confounding an association between two variables because others are not controlled. 
Correspondence analysis (Hobbs and Williamson, 2003) and cluster analysis (Williamson et al., 1996) can be more appropriate as they consider all of the possible categories at the same time. Other techniques such as structural equation modelling have also been applied (Katsakiori et al., 2010).

Probably the most useful method for presentation purposes is correspondence analysis because the plots are very intuitive. Correspondence analysis is a multivariate statistical technique. Conceptually similar to principal component analysis, but applies to categorical rather than continuous data. In a similar manner to principal component analysis, it provides a means of displaying or summarising a set of data in two-dimensional graphical form. The nearest two modalities are in the plot, the stronger is the evidence of the relationship between them.

For example, the correspondence plot between deviations and type of causes for maintenance accidents (see Figure 1) shows that accidents with loss of control as a deviation a near to the type of causes related to equipment in bad condition.

Figure 1 Correspondence plot example: deviation and group of causes

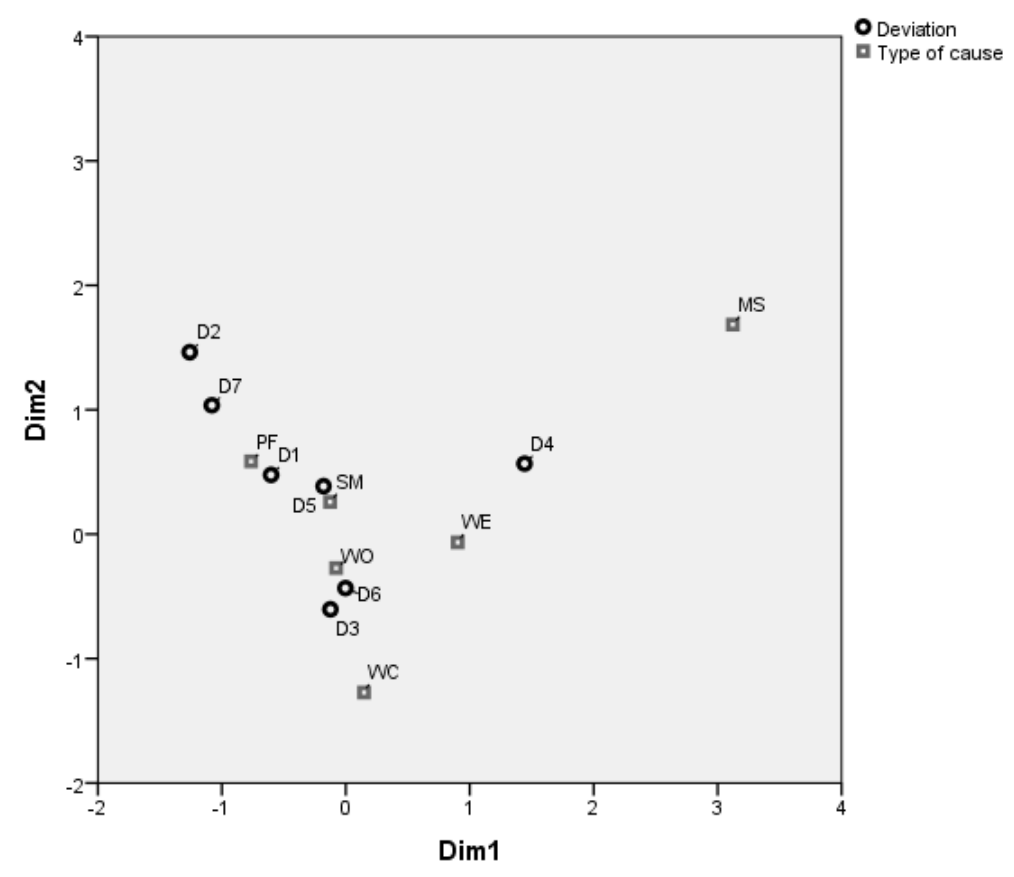

Notes: Deviations. D1: deviation due to electrical problems, explosion, fire; D2:

deviation by overflow, overturn, leak, flow, vaporisation, emission; D3: breakage, bursting, splitting, slipping, fall, collapse of material agent; D4: loss of control (total or partial) of machine, means of transport or handling equipment, handheld tool, object, animal; D5: Slipping - stumbling and falling - fall of persons; D6: body movement without any physical stress (generally leading to an external injury); D7: body movement under or with physical stress (generally leading to an internal injury). Groups of causes. WC: workplace conditions; WE: work equipment; MS: material and substances; WO: work organisation; SM: safety management; PF: personal factors. 


\section{Discussion}

A good design of a public programme of learning from accidents needs certain requisites. Without a proper definition of the objectives and the method of investigation it is not possible to coherently and consistently gather data. Moreover, without a proper codification of the causes and accident scenarios it is not possible to analyse the data gathered.

The occupational accidents are unfortunately too frequent and the scenarios too different so the best approach is epidemiological. Therefore, the analysis and the learning process can be done through public programmes such as those designed in Andalusia.

With that approach, the initial results of the programme have covered the differential causation for specific accident mechanisms (Carrillo-Castrillo et al., 2013), for specific collective of workers (Carrillo et al., 2013) or specific organisation types (Carrillo and Onieva, 2012). These initial results demonstrate the usefulness of the design of the programme and the potential use of the coded causes for epidemiological statistical analysis of the causation patterns.

Small and medium enterprises need public programmes that help them to identify the main potential causes of accidents in order to prioritise the countermeasures. At the same time, public agencies can prioritise the promotion of programmes in order to assess enterprises.

The epidemiological approach not only provides the most frequent causes, but also identify for each accident scenario (task and accident mechanism) and each type of worker or organisation which are the most likely causes. Safety assessment should take into account most frequent causes of accidents in the manufacturing sector and their relationship with work scenarios. This means, in terms of safety assessment, organisations with those possible scenarios of accident should concentrate their efforts on eliminating, if possible, the causes most prevalent for those scenarios.

It is worth noting that there is a causation pattern in the accidents investigated and that the most prevalent causation patterns alerts enterprises and public agencies of their complexity. According to the accidents analysed in the programme so far, in most of cases there is at least one latent cause identified. Without latent causes only $9 \%$ of the accidents can be explained. Moreover, in $60 \%$ of the accidents the main cause was latent. These results show that latent causes are the starting point of most of accidents and that even in the manufacturing sector, prevention based only in the technological system and the physical barriers is not enough to prevent severe accidents.

A strong relationship between organisational and safety management deficiencies and immediate causes of accidents has been found. According to the accident investigation reports, latent causes are associated to active causes. In this aspect, adoption of safety management models and audits on safety management are highly recommended. First, because any adequate safety system as preventive activities should help to eliminate active causes. This is the underlying reason for the strong association between organisational and safety management causes and active causes. Second, because latent causes are also contributing risk factors of accident occurrence.

These first results are promising. As for any public programme it would need to be evaluated for efficiency. This evaluation should deal with the impact of the programme in the daily activities of safety practitioners and the impact of the conclusions in the safety management of enterprises in Andalusia. 
International organisations should promote shared initiatives to gather and analyse results from public occupational accident investigations. Similar programmes, such as in maritime, nuclear or major accidents provide a useful framework for learning. If possible, an international consensus is needed for common cause identification and coding in order to make the results comparable. Public health and safety agencies have been gathering circumstances of occupational accidents for a long time and now is the time for gathering causes and causation patterns. If so, learning from accidents would be properly developed and safety practitioners and enterprises would be able to prevent causes of accidents even without experiencing them.

\section{References}

Aneziris, O., Papazoglou, I. and Doudakmani, O. (2010) 'Assessment of occupational risks in an aluminium processing industry', International Journal of Industrial Ergonomics, Vol. 40, No. 3, pp.321-329.

Carrillo, J.A. and Onieva, L. (2012) 'Organizational causes of accidents in the manufacturing sector', in 6th International Conference on Industrial Engineering and Industrial Management-CIO2012: Book of Full Papers, Adingor, Vigo.

Carrillo, J.A., Rubio-Romero, J.C., López-Arquillos, A. and Onieva, L. (2013) 'The role of worker individual characteristics in the severe injuries causation in the Andalusian manufacturing sector', in Arezes, P. et al. (Eds.): Occupational Safety and Hygiene - SHO2013, Portuguese Society of Occupational Safety and Hygiene, Guimaraes.

Carrillo-Castrillo, J.A., Rubio-Romero, J.C. and Onieva, L. (2013) 'Causation of severe and fatal accidents in the manufacturing sector', International Journal of Occupational Safety and Ergonomics, Vol. 19, No. 3, pp.423-434.

Chi, C-F., Yang, C-C. and Chen, Z-L. (2009) 'In-depth accident analysis of electrical fatalities in the construction industry', International Journal of Industrial Ergonomics, Vol. 39, No. 4, pp.635-644.

European Commission (2002) European Statistics on Accidents at Work (ESAW) - Methodology, 2001 ed., Office for Official Publications of the European Communities, Luxembourg.

European Commission (2009) Causes and Circumstances of Accidents at Work in the EU, Office for Official Publications of the European Communities, Luxembourg.

Fraile, A. (2011) NTP924: Causas de Accidentes: Clasificación y Codificación, Instituto Nacional de Seguridad e Higiene en el Trabajo, Madrid.

Hale, A.R., Ale, B.J.M., Goossens, L.H.J., Heijer, T., Bellamy, L.J., Mud, M.L., Roelen, A., Baksteen, H., Post, J., Papazoglou, I.A., Bloemhoff, A. and Oh, J.I.H. (2007) 'Modeling accidents for prioritizing prevention', Reliability Engineering and System Safety, Vol. 92, No. 12, pp.1701-1715.

Higgins, D.N., Casini, V.J., Bost, P. et al. (2001) 'The fatality assessment and control evaluation program's role in the prevention of occupational fatalities', Injury Prevention, Vol. 1, No. 7, Suppl I, pp.27-33.

Hobbs, A. and Williamson, A. (2003) 'Associations between errors and contributing factors in aircraft maintenance', The Journal of the Human Factors and Ergonomics Society, Vol. 45, No. 2, pp.186-201.

Hollnagel, E. (2008) 'The changing nature of risks', Ergonomics Australia, Vol. 22, Nos. 1-2, pp.33-46.

Høyland, A. and Rausand, M. (1994) System Reliability Theory: Models and Statistical Methods, Wiley, New York.

International Labour Organization (1998) Encyclopaedia of Occupational Health and Safety, International Labour Organization, Geneva. 
Jacinto, C. and Aspinwall, E. (2003) 'Work accidents investigation technique (WAIT)', Safety Science Monitor, Vol. 7, No. 1, Article IV-2, 1-17 [online] http://ssmon.chb.kth.se/vol7/42.pdf.

Jacinto, C., Canoa, M. and Guedes-Soares, C. (2009) 'Workplace and organizational factors in accident analysis within the Food industry', Safety Science, Vol. 47, No. 5, pp.626-635.

Jacinto, M.C. and Aspinwall, E. (2004) 'A survey on occupational accidents' reporting and registration systems in the European Union', Safety Science, Vol. 42, No. 10, pp.933-960.

Junta de Andalucia (2012) Official accident investigations repository 'Pudo haberse evitado' [online]

http://www.juntadeandalucia.es/organismos/economiainnovacioncienciayempleo/areas/segurid ad-salud/informacion/paginas/pudo-haberse-evitado.html (accessed 31 December 2012).

Katsakiori, P., Kavvathas, A., Athanassiou, G., Goutsos, S. and Manatakis, E. (2010) 'Workplace and organizational accident causation factors in the manufacturing industry', Human Factors and Ergonomics in Manufacturing and Service Industries, Vol. 20, No.1, pp.2-9.

Katsakiori, P., Sakellaropoulos, G. and Manatakis, E. (2009) 'Towards an evaluation of accident investigation methods in terms of their alignment with accident causation models', Safety Science, Vol. 47, No.7, pp.1007-1015.

Khanzode, V.V., Maiti, J. and Ray, P. (2012) 'Occupational injury and accident research: a comprehensive review', Safety Science, Vol. 50, No. 5, pp.1355-1367.

Kines, P. (2002) 'Construction workers' falls through roofs: fatal versus serious injuries', Journal of Safety Research, Vol. 33, No. 2, pp.195-208.

Lincoln, A.E., Sorock, G.S. and Courtney, T.K. (2004) 'Using narrative text and coded data to develop hazard scenarios for occupational injury interventions', Injury Prevention, Vol. 10, No. 4, pp.249-254.

Reason, J. (2000) 'Human errors: models and management', British Medicine Journal, Vol. 320, No. 7237, pp.768-770.

Shappell, S.A. and Wiegmann, D.A. (2001) 'Applying reason: the human factors analysis and classification system (HFACS)', Human Factors and Aerospace Safety, Vol. 1, No. 1, pp.59-86.

Sklet, S. (2004) 'Comparison of some selected methods for accident investigation', Journal of Hazardous Materials, Vol. 111, Nos. 1-3, pp.29-37.

The Sixteenth International Conference of Labour Statisticians (1998) Final Report of the Sixteenth International Conference of Labour Statisticians, International Labour Organization, Geneva.

Van Wassenhove, W. and Wybo, J-L. (2002) 'Methodology of organizational learning in risk management: development of a collective memory for sanitary alerts', in TIEMS 2002 - The International Emergency Management Society Conference.

Williamson, A.M., Feyer, A-M. and Cairns, D.R. (1996) 'Industry differences in accident causation', Safety Science, Vol. 24, No. 1, pp.1-12.

Willquist, P. and Törner, M. (2003) 'Identifying and analyzing hazards in manufacturing industry a review of selected methods and development of a framework for method applicability', International Journal of Industrial Ergonomics, Vol. 32, No. 3, pp.165-180. 


\section{Annex}

Table A1 Causes codification system used

1 Workplace conditions

11 Workplace design

1101 Deficient ergonomic design of workstation.

1102 Unstable work surface.

1103 Lack of adequate space in workstations or traffic areas.

1104 Lack of overall protection to prevent falls from a height.

1105 Unprotected openings and holes.

1106 Poor structural strength or stability of coverings.

1107 Lack of weight limit signage on work surface.

1108 Poor shoring of ditches or inadequate sloping.

1109 Difficult access to workstation.

1110 Inadequate pavement.

1111 Unsafe ladders.

1112 Non-existent or insufficient signage of evacuation routes.

1113 Poor design of evacuation routes.

1114 Non-existent, insufficient or ineffective separation or isolation of high-risk areas, such as zoning for explosive atmospheres, confined spaces or extremely hot or cold areas, etc.

1115 Poor or non-existent signage for delimitation of the work space.

1116 Inadequate traffic positioning and routes.

1117 Poor design of windows.

1118 Poor design of doors.

1199 Other causes related to workplace design.

12 Housekeeping

1201 Deficient housekeeping.

1202 Inadequate drainage system.

1203 Lack of proper separation between workstation and traffic areas.

1299 Other causes related to housekeeping.

13 Physical agents

1301 Noise.

1302 Vibrations.

1303 Ionising radiation.

1304 Non-ionising radiation.

1305 Insufficient or inappropriate lighting.

1306 Glares.

1307 Causes related to thermo-hygrometric conditions.

1308 Causes related to meteorological aspects.

1309 Lack of protection against physical agents.

1399 Other causes related to physical agents.

Source: Fraile (2011) 
Table A1 Causes codification system used (continued)

19 Other causes related to workplaces

1999 Other causes related to workplaces.

2 Service and protection facilities

21 Service and protection facilities: design, installation and maintenance

2101 Unplanned shutdown of facilities (electricity, gas, water).

2102 Lack of low-voltage facilities.

2103 Defective electrical facilities.

2104 Lack of proper equipment for preventing static electricity.

2105 Lack of proper fire detection and warning systems.

2106 Storage of flammable chemicals near fire hazards without proper controls.

2107 Lack of explosion-proof facilities in potentially explosive atmospheres.

2108 Impediments to proper maintenance of service or protection facilities.

2109 Poor condition of service or protection facilities due to other causes.

2110 Lack of sealed containment areas for storing chemical products.

2111 Inadequate tanks and containers.

2112 Inadequate piping systems.

2199 Other causes related to design, installation and maintenance of service and protection facilities.

22 Service and protection facilities: protective devices

2201 Non-existent or insufficient protective measures and devices for preventing direct electric contacts.

2202 Deficient isolation or inadequate electrical protection.

2203 Malfunctioning or lack of protective devices for preventing indirect electric contacts.

2204 Malfunctioning or lack of devices for preventing static electric accumulation.

2205 Lack of omnipolar cut-off switch.

2206 Lack of protective devices for preventing electric overload or short-circuits.

2207 Lack of protective devices for excess pressure, such as valves or vents.

2208 Poor fire fighting equipment.

2209 Poor ventilation impeding the prevention of dangerous environments.

2210 Broken interlock devices.

2299 Other causes related to protective devices in service or protection facilities.

23 Service and protection facilities: signage and information

2301 Poor identification of wires.

2302 Poor identification of dangerous piping.

2303 Poor signage of fire fighting equipment.

2399 Other causes related to signage and information in service or protection facilities.

29 Service and protection facilities: other causes

2999 Other causes related to service or protection facilities.

Source: Fraile (2011) 
Table A1 Causes codification system used (continued)

3 Machinery

31 Machinery: design, installation and maintenance

3101 Deficient design that does not comply intrinsic safety principles or ergonomics.

3102 Hazardous modifications made to machinery, against recommendations of the manufacturer.

3103 Inadequate positioning of machinery.

3104 Lack of stability in the machinery.

3105 Insufficient mechanical strength of machinery.

3106 Poor design of machinery relating to pressure, temperature or chemicals.

3107 Ignition sources not controlled (mechanical, electrical, thermal or chemical causes)

3108 Failures in hydraulic, pneumatic or electric systems in the machinery.

3109 Unsafe switches or controls.

3110 Lack of stop or control devices, excluding emergency stops.

3111 Accessible hazardous parts

3112 Insufficient safeguards or proper isolation for cold/hot parts or hazardous substances.

3113 Poor design for accessing the machinery.

3114 Lack of adequate visibility for the driver in mobile machines.

3115 Inadequate driving system, brake system or clutch system in mobile machines.

3116 Poor design impeding safe maintenance or cleaning of the machine.

3117 Inadequate installation or assembly of machines.

3118 Inadequate system for hitching/unhitching machinery.

3119 Protective device or control device with a low category.

3199 Other causes related to the design, installation and maintenance of machinery.

32 Machinery: protective devices

3201 Lack of safeguards or protective devices.

3202 Non-existent, ineffective, or inaccessible emergency stop.

3204 Non-existent or inadequate rolling objects protection system to prevent roll-over of mobile machinery (r.o.p.s.).

3205 Non-existent or inadequate falling object protection system to protect from falling objects (f.o.p.s.).

3206 Lack of lock-out/tag-out systems.

3207 Lack of devices to prevent the machine from being used by unauthorised workers.

3208 Lack of devices for the proper transport of workers in mobile machinery.

3299 Other causes related to protective devices for machinery.

33 Machinery: signage and information

3301 Lack of alarms or warnings.

3302 Lack of user instructions for machinery.

3999 Other causes related to machinery. 
Table A1 Causes codification system used (continued)

4 Other work equipment

41 Other work equipment: design, installation and maintenance

4101 Deficient design that does not comply intrinsic safety principles or ergonomics.

4102 Inadequate positioning or stability of other work equipment.

4103 Insufficient strength in other work equipment.

4104 Inadequate design for pressure, temperature or chemicals of other work equipment.

4105 Accessible hazardous parts of other work equipment.

4106 Unsafe ladders.

4199 Other causes related to design, installation and maintenance of other work equipment.

42 Other work equipment: protective devices

4201 Lack of safety devices in lifting equipment.

4202 Lack of protection elements in tools.

4203 Lack of overall protection systems to prevent falls from a height.

4299 Other causes related to protective devices of other work equipment.

43 Other work equipment: signage and information

4301 Lack of instructions or signage.

4302 Lack of signage and information related to maximum load for lifting devices.

4399 Other causes related to signage and information for other work equipment.

49 Other work equipment: other causes

4999 Other causes related to other work equipment.

5 Materials and agents

51 Storage and handling of materials

5101 Defective materials.

5102 Inadequate equipment for storage and handling relating to materials.

5103 Lack of technical equipment for loading/unloading operations.

5104 Poor storage and handling systems.

5105 Inadequate storage areas.

5106 Poor planning and supervision of lifting tasks.

5199 Other causes related to storage and handling of materials.

52 Chemical agents

5201 Inhalation, ingestion or contact with chemical agents.

5202 Inadequate procedures for storage and handling of chemicals.

5203 Presence of non-controlled chemical agents.

5204 Poor control of hazardous products that can lead to a major accident.

5205 Poor control of flammable or explosive chemical products.

5206 Insufficient control of possible contacts or mixtures of chemical products that could have dangerous reactions.

Source: Fraile (2011) 
Table A1 Causes codification system used (continued)

5207 Leakage or overflow of chemical products.

5208 Inadequate labelling and packaging of chemical products transferred internally by the enterprise.

5209 Inadequate labelling and packaging of chemical products excluding those transferred internally by the enterprise.

5210 Poor control of the generation and propagation of chemical agents.

5299 Other causes related to chemical agents.

53 Biological agents

5301 Contact with or presence of animals.

5302 Lack of control for biological agents or living beings sensitive to infection.

5303 Poor protection against the spread of biological agents.

5304 Poor personal hygiene measures.

5399 Other causes related to biological agents.

59 Other causes related to materials and agents

5999 Other causes related to materials and agents.

6 Work organisation

61 Work methods

6101 Lack of work methods.

6102 Inadequate work methods.

6103 Inadequate design of task or work.

6104 High work speed.

6105 Monotonous or routine work without proper countermeasures.

6106 Solitary work without proper countermeasures.

6107 Overload regarding the limits or specifications of the equipment.

6108 Worker overload, either physical or mental.

6109 Poor coordination among workers performing tasks.

6110 Lack of proper supervision.

6111 Work organisation without consideration for meteorological conditions.

6199 Other causes related to work methods.

62 Carrying out tasks

6201 Unusual task for the worker.

6202 Task performed to avoid or resolve breakdowns, failures or incidents.

6203 Unusual task performed during an accident or emergency.

6299 Other causes related to task organisation.

63 Task training or information

6301 Poor communication, including language comprehension.

6302 Lack of instructions.

6303 Inadequate instructions given for the task. 
Table A1 Causes codification system used (continued)

6304 Inadequate training or information given for the task.

6305 Poor procedures for training or informing workers regarding equipment and materials.

6306 Lack of proper signage or information for workers.

6307 Poor traffic or load signage.

6308 Poor lock-out tagging to avoid unexpected power usage.

6399 Other causes related to task training or information.

64 Equipment and material selection

6401 Appropriate equipment not provided.

6402 Selection of machines not appropriate to the task.

6403 Selection of equipment not appropriate to the task.

6404 Poor selection of materials.

6405 Inappropriate use of a machine, against manufacturer recommendations.

6406 Inappropriate use of equipment, against manufacturer recommendations.

6407 Use of general materials against manufacturer recommendations.

6408 Equipment not checked before use.

6409 Poor lock-out/tag-out procedures.

6499 Other causes related to the selection and use of equipment and materials.

69 Other organisational causes

6999 Other organisational causes.

7 Safety system

71 Safety management

7101 Poor procedures for risk assessment.

7102 Poor procedures for planning and implementing safety practices.

7103 Inadequate procedures for training and informing workers about risks and preventive measures.

7104 Inadequate organisation for performing the preventive measures.

7105 Inadequate procedures for the coordination of activities involving different enterprises.

7106 Inadequate purchasing practices regarding prevention.

7107 Inadequate matching of workers and tasks, not including criteria related to training or qualifications.

7108 Failing to identify workers with inadequate characteristics regarding the nature of the task or the risks involved.

7199 Other causes related to safety management.

72 Safety activities

7201 Hazards not identified during the risk assessment.

7202 Inadequate planning of preventive measures relating to poor assessment or identification of risks.

Source: Fraile (2011) 
Table A1 Causes codification system used (continued)

7203 Poor implementation of the preventive measures planned.

7204 Lack of checks for safety plans in construction activities.

7205 Inadequate maintenance.

7206 Inadequate training or information regarding risks or the preventive measures.

7207 Inadequate emergency planning.

7208 Adequate personnel protective equipment (PPE) not provided or poor supervision of their use.

7209 Insufficient presence of preventative safety resources.

7210 Inadequate health supervision in relation to risks.

7211 Lack of adequate work permissions and/or procedures involving dangerous tasks.

7212 Task assigned to a worker without adequate qualifications or experience.

7299 Other causes related to safety activities.

8 Personal factors

81 Behaviour

8101 Performing non-assigned tasks.

8102 Failure to comply with work procedures.

8103 Failure to comply with safety rules.

8104 Inadequate use of material or equipment.

8105 Inadequate use of auxiliary devices.

8106 Failure to use personal protective equipment.

8107 Removal or override of safeguards or protective devices.

8108 Worker presence in a dangerous or unauthorised area.

8109 Inadequate posture in the workstation.

8199 Other causes related to behaviour.

82 Intrinsic factors

8201 Lack of proper physical or mental conditions for performing the task.

8202 Poor understanding of instructions.

8203 Lack of worker qualifications or experience.

8299 Other causes related to intrinsic factors.

89 Other personal factors

8999 Other causes related to personal factors.

9 Other causes

91 Non-causal facts

9199

92 Other causes

Source: Fraile (2011) 